\title{
Synergistic cytotoxicity of the CDK4 inhibitor Fascaplysin in combination with EGFR inhibitor Afatinib against Non-small Cell Lung Cancer
}

\author{
Adelina Plangger ${ }^{1} \cdot$ Barbara Rath $^{1} \cdot$ Maximilian Hochmair ${ }^{2} \cdot$ Martin Funovics $^{3} \cdot$ Christoph Neumayer $^{4}$. \\ Robert Zeillinger $^{5} \cdot$ Gerhard Hamilton $^{1}$ (1)
}

Received: 11 November 2020 / Accepted: 16 September 2021 / Published online: 1 October 2021

(c) The Author(s) 2021

\begin{abstract}
Summary
In the absence of suitable molecular markers, non-small cell lung cancer (NSCLC) patients have to be treated with chemotherapy with poor results at advanced stages. Therefore, the activity of the anticancer marine drug fascaplysin was tested against primary NSCLC cell lines established from pleural effusions. Cytotoxicity of the drug or combinations were determined using MTT assays and changes in intracellular phosphorylation by Western blot arrays. Fascaplysin revealed high cytotoxicity against NSCLC cells and exhibit an activity pattern different of the standard drug cisplatin. Furthermore, fascaplysin synergizes with the EGFR tyrosine kinase inhibitor (TKI) afatinib to yield a twofold increased antitumor effect. Interaction with the Chk1/2 inhibitor AZD7762 confirm the differential effects of fascplysin and cisplatin. Protein phosphorylation assays showed hypophosphorylation of Akt1/2/3 and ERK1/2 as well as hyperphosphorylation of stress response mediators of H1299 NSCLC cells. In conclusion, fascaplysin shows high cytotoxicity against pleural primary NSCLC lines that could be further boosted when combined with the EGFR TKI afatinib.
\end{abstract}

Keywords Non-small cell lung cancer $\cdot$ Pleural effusion $\cdot$ Fascaplysin $\cdot$ Afatinib $\cdot$ Cytotoxicity $\cdot$ Protein phosphorylation

\section{Introduction}

This preclinical work does not include any treatment of patients and is not part of any interventional study.

Gerhard Hamilton

gerhard.hamilton@meduniwien.ac.at

1 Institute of Pharmacology, Medical University of Vienna, Vienna, Austria

2 Department of Respiratory \& Critical Care Medicine, Karl Landsteiner Institute of Lung Research \& Pulmonary Oncology, Vienna, Austria

3 Division of Cardiovascular and Interventional Radiology, Department of Biomedical Imaging and Image-Guided Therapy Medical, University of Vienna, Vienna, Austria

4 Department of Vascular Surgery, Medical University of Vienna, Vienna, Austria

5 Molecular Oncology Group, Department of Obstetrics and Gynecology, Medical University of Vienna, Vienna, Austria
Approximately $80 \%$ of all lung cancers are of the Non-small Cell Lung Cancer (NSCLC) type that is often detected at an advanced stage and portends a dismal prognosis [1]. The standard first-line therapy employing platinum-based chemotherapy resulted in minor improvements in survival but at the cost of side effects and poorer quality of life (QoL). The platinum drug combinations with either gemcitabine, docetaxel or pemetrexed have reached a plateau offering a mean survival of approximately one year in advanced NSCLC [2]. Patients expressing immune checkpoint markers are amenable to treatment with monoclonal antibodies [3, 4]. The focus of NSCLC treatment shifted significantly with availability of inhibitors of targetable driver kinases such as mutated epidermal growth factor (EGFR) and anaplastic lymphoma kinase (ALK) rearrangements, among others [5].

The first-generation EGFR tyrosine kinase inhibitors (TKIs) gefitinib and erlotinib bind reversibly to the kinase domain of the receptor, but second-generation drugs such as the pan-ErbB inhibitor afatinib show irreversible inhibition of the kinase activity [6]. In NSCLC, pancreatic cancer and 


\section{IC 50 Fascaplysin}

a

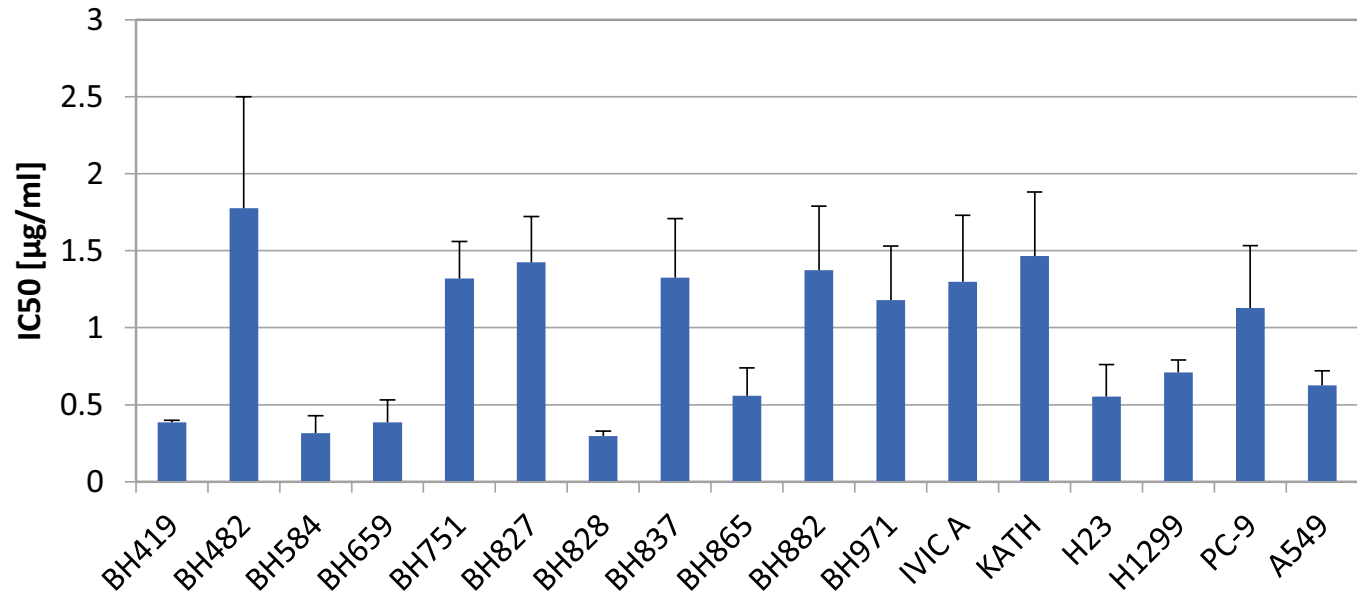

IC 50 Cisplatin

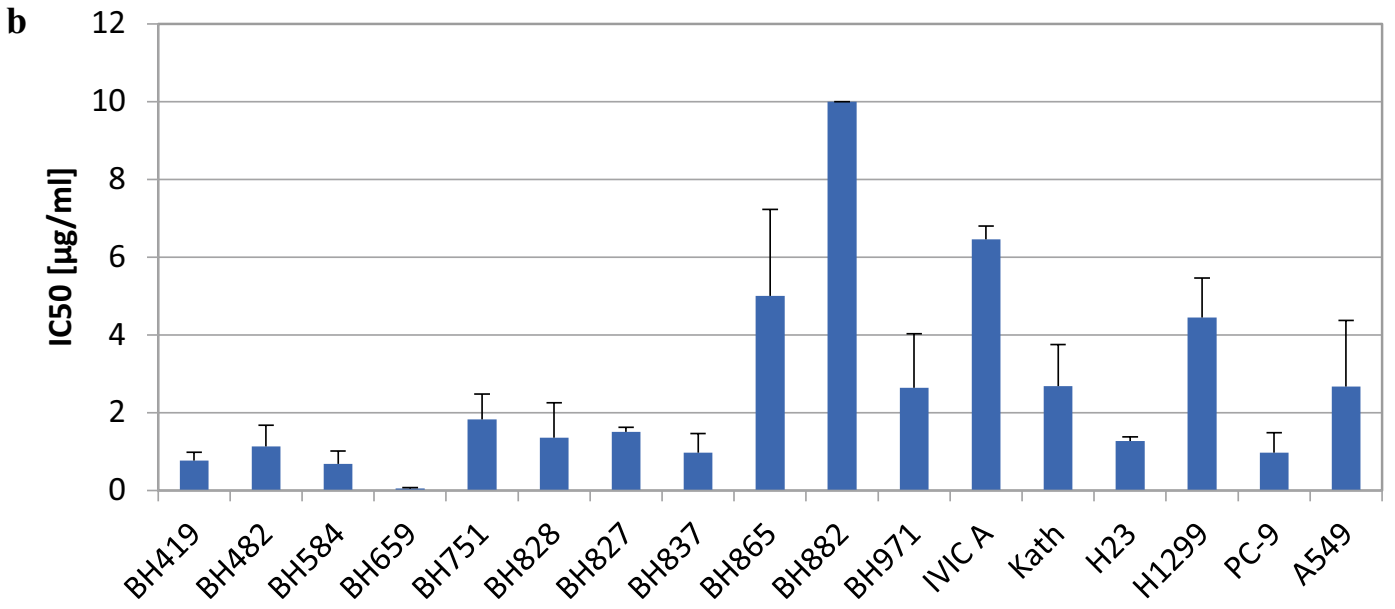

IC 50 Afatinib

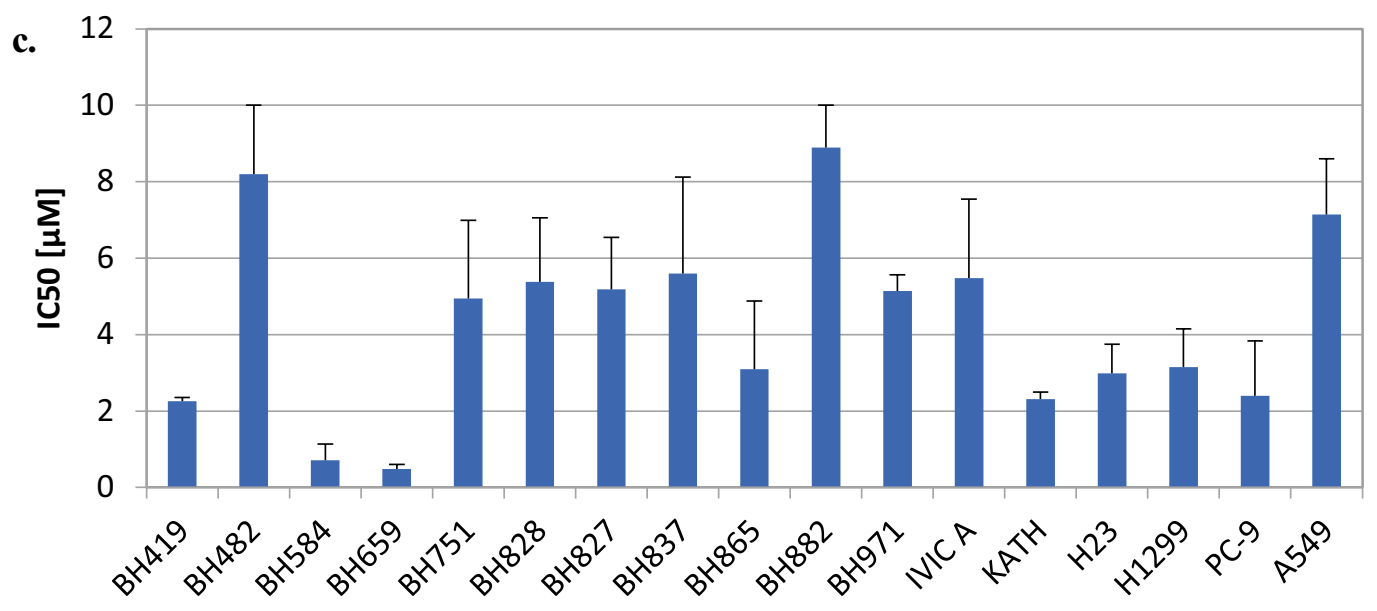


4Fig. 1 a-c. The figure show the $\mathrm{IC}_{50}$ values for fascaplysin (1a), cisplatin (1b) and afatinib (1c), for the panel of pleural primary NSCLC cell lines and H23, H1299, PC-9 and A549 permanent NSCLC lines, respectively. Data shown represent mean values \pm SD

colorectal cancer, afatinib resulted in an inhibition of cellular growth and induction of apoptosis [7]. Although afatinib is most effective against mutated EGFR it is likewise active against the wildtype receptor. Unfortunately, the majority of NSCLC lacks actionable drivers and still have to be treated with cytotoxic combination chemotherapy. However, durable disease control is rare and the 5-year survival is below $5 \%$ [8]. Therefore, new agents with different mechanisms of antitumor activity may improve outcomes of NSCLC patients.

A range of antitumor compounds has been extracted from the sponge Fascaplysinopsis spp. with fascaplysin (12,13-dihydro-13-oxo-pyrido[1,2-a:3,4-b'] diindol-5-ium monochloride) as the most important agent [9]. Fascaplysin and derivatives exhibits a multitude of biological activities including antitumor effects based on antiproliferative and anti-angiogenic properties via targeting of cyclin-dependent kinase-4 (CDK4; $\mathrm{IC}_{50} 350 \mathrm{nM}$ ) and by intercalation into DNA [10, 11]. Furthermore, fascaplysin increases phosphorylation of Akt, and adenosine monophosphate-activated protein kinase (AMPK), which are essential due to their anti-apoptotic or pro-survival functions in cancer [12]. Fascaplysin inhibited ovarian cancer cell proliferation, invasion and migration and suppressed CDK4, cyclin D1, Bcl-2, and VEGF-A expression [13, 14].

Our previous studies revealed that fascaplysin exhibited high cytotoxicity against Small Cell Lung Cancer (SCLC) cell lines (mean $\mathrm{IC}_{50} 0.89 \mu \mathrm{M}$ ) and against SCLC Circulating Tumor Cell (CTCs) lines (mean $\left.\mathrm{IC}_{50} 0.57 \mu \mathrm{M}\right)[15,16]$. Selected NSCLC lines exhibited a mean $\mathrm{IC}_{50}$ of $1.15 \mu \mathrm{M}$ for fascaplysin and the compound showed an additive cytotoxic effect with cisplatin. Available permanent cancer cell lines have been adapted for vigorous in vitro growth and may not be truly representative of the in vivo situation in patients. Acquisition of NSCLC cells for tests is possible by routine thoracentesis in patients with advanced NSCLC. Malignant pleural effusion (MPE) is observed in half of advanced NSCLC cases and is associated with a short survival [17]. MPE samples frequently contain numerous tumor cells, that allow for the determination of driver gene status and chemosensitivity [18-20]. In the present study, a panel of primary NSCLC lines from pleural effusions was employed to compare their chemosensitivity against fascaplysin with that for cisplatin. Furthermore, both drugs were combined with the afatinib to test a possible synergistic activity and with the Chk1/2 inhibitor AZD7762 to investigate DNA damagemediated drug effects. The results demonstrate that afatinib acts synergistically with fascaplysin to sensitize the NSCLC cancer cells against this marine drug.

\section{Materials and methods}

Cell Culture and reagents Unless otherwise noted, all chemicals were obtained from Sigma-Aldrich (St. Louis, MO, USA). Dulbecco's phosphate buffered saline (PBS) was purchased from Gibco/Invitrogen (Carlsbad, CA, USA). Compounds were prepared as stock solutions of $2 \mathrm{mg} / \mathrm{mL}$ in either DMSO or $0.9 \% \mathrm{NaCl}$ for cisplatin and aliquots stored at $-20{ }^{\circ} \mathrm{C}$. Equivalent concentrations of DMSO were supplemented to medium controls. Established permanent cell lines were obtained from the American Type Culture Collection (Manassas, VA, USA) and primary lung cancer lines were established in our lab. Collection of pleural effusions of lung cancer patients, isolation of tumor cells and generation of cell lines was done according to the Ethics Approval 366/2003 by the Ethics Committee of the Medical University of Vienna, Vienna, Austria. In brief, pleural effusions were centrifuged and the tumor cells washed with tissue culture medium consisting of RPMI-1640 medium, supplemented with $10 \%$ FBS (Seromed, Berlin, Germany) and antibiotics
Fig. 2 Overview of the CI values for the fascaplysin afatinib combinations (mean values $\pm \mathrm{SD}$. Values below 1 indicate a synergistic interaction

\section{Fascaplysin/Afatinib Combination}

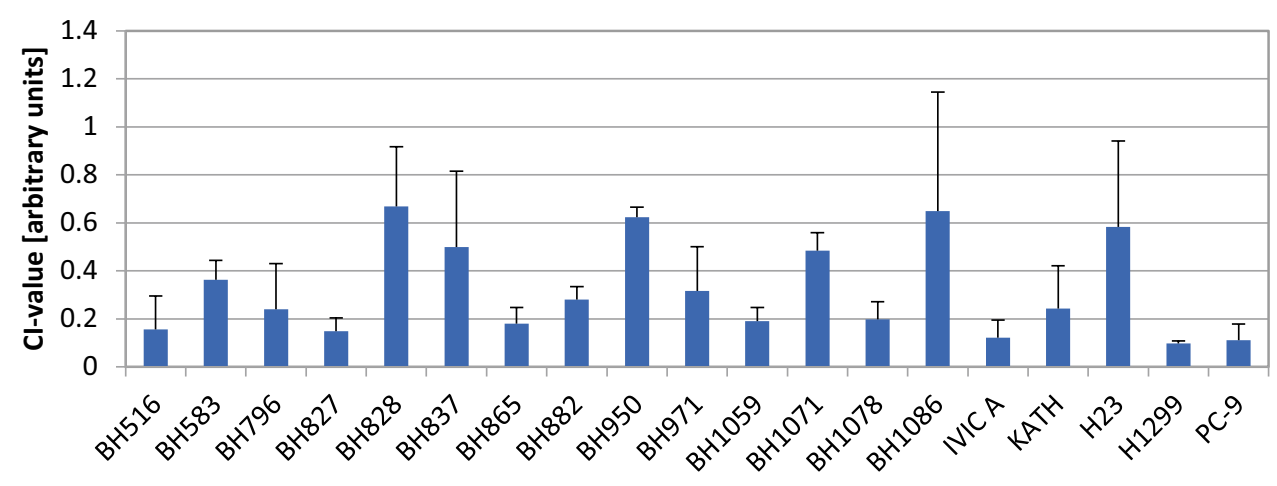


(final concentrations: $50 \mathrm{U} / \mathrm{mL}$ of penicillin, $50 \mu \mathrm{g} / \mathrm{mL}$ of streptomycin, and $100 \mu \mathrm{g} / \mathrm{mL}$ neomycin). When required, erythrocytes were removed by Histopaque ${ }^{\circledR}-1077$ (SigmaAldrich) gradient centrifugation. Primary NSCLC cell lines were established in tissue culture medium and cultures split by trypsination. All cell lines showed an EGFR del19 deletion, with exception of BH1059/RET mutation, BH419 BRCA1 mutation and three lines, namely BH482, BH583 and $\mathrm{BH} 827$, with ALK rearrangements.

Phosphokinase Array Relative protein phosphorylation levels of 38 selected proteins were obtained by analysis of 43 specific phosphorylation sites using the Proteome Profiler Human Phospho-Kinase Array Kit ARY003B/C (R\&D Systems, Minneapolis, MN, USA) in duplicate tests carried out according to the manufacturer's instructions. Briefly, cells were rinsed with PBS, $1 \times 10^{7}$ cells $/ \mathrm{mL}$ lysis buffer were solubilized under permanent shaking at $4{ }^{\circ} \mathrm{C}$ for $30 \mathrm{~min}$, and aliquots of the lysates were stored frozen at $-80^{\circ} \mathrm{C}$. After blocking, membranes with spotted catcher antibodies were incubated with diluted cell lysates at $4{ }^{\circ} \mathrm{C}$ overnight. Thereafter, cocktails of biotinylated detection antibodies were added at room temperature for $2 \mathrm{~h}$. Phosphorylated proteins were revealed using streptavidin-HRP/chemiluminescence substrate (SuperSignal West Pico, Thermo Fisher Scientific, Rockford, IL, USA) and detection with a Molecular Imager ChemiDoc MP imaging system (Bio-Rad, Hercules, CA, USA). Images were quantified using Image J (NIH, Bethesda, MD, USA) and Origin (OriginLab, Northampton, MA, USA) software. The different Western blot membranes were normalized using the 6 calibration spots included.

Cytotoxicity Assay Aliquots of $1 \times 10^{4}$ cells in 200 $\mu \mathrm{L}$ medium were treated for four days with twofold dilutions of the test compounds in 96-well microtiter plates in quadruplicate (TTP, Trasadingen, Switzerland). The plates were incubated under tissue culture conditions and cell viability was measured using a modified MTT (3-(4,5-dimethylthiazol-2-yl)-2,5-diphenyltetrazolium bromide) assay (EZ4U, Biomedica, Vienna, Austria). Optical density was measured using a microplate reader at $450 \mathrm{~nm}$ and values obtained from control wells containing cells and media alone were set to $100 \%$ proliferation. For the assessment of the interaction of the test compounds, tests were performed comprising the individual drugs alone and in combination, followed by analysis using the Chou-Talalay method with help of the Compusyn software (ComboSyn Inc., Paramus, NJ, USA).

Statistics Statistical analysis was performed using Student's $t$ test for normally distributed samples $(* p<0.05$ was regarded as statistically significant). Values are shown as mean \pm SD.

\section{Results}

\section{Cellular toxicity of fascaplysin, cisplatin and afatinib}

Cytotoxicity of fascaplysin, cisplatin and afatinib were determined in MTT assays employing primary NSCLC cell lines and the permanent NSCLC cell lines H23, H1299, PC9 and A549 (Fig. 1A-C). $\mathrm{IC}_{50}$ values for fascaplysin varied from $0.48-1.37 \mu \mathrm{g} / \mathrm{ml}$, with $8 / 17$ cell lines exhibiting high chemosensitivity (Fig. 1A). A group of cell lines with high sensitivity of $0.48 \pm 0.14 \mu \mathrm{g} / \mathrm{ml}$ contrasts to a more resistant NSCLC cell population exhibiting a mean $\mathrm{IC}_{50}$ value of $1.37 \pm 0.18 \mu \mathrm{g} / \mathrm{ml}(\mathrm{p}=0.001)$. The difference in fascaplysin sensitivity of the permanent cell line H23, H1299, PC-9 and A549 versus primary NSCLC lines is not statistically different.

The $\mathrm{IC}_{50}$ values for cisplatin show a distinct sensitivity pattern for the NSCLC cell lines tested (range: 1.42
Fig. 3 shows the CI values for the fascaplysin-AZD7762 combinations and the panel of NSCLC lines under investigation. Data represent mean values \pm SD. Differences between fascaplysin/cisplatin AZD7762 were significant for all combinations, except for BH751, BH865, H23 and H1299

\section{Fascaplysin/AZD7762 vs Cisplatin/AZD7762}

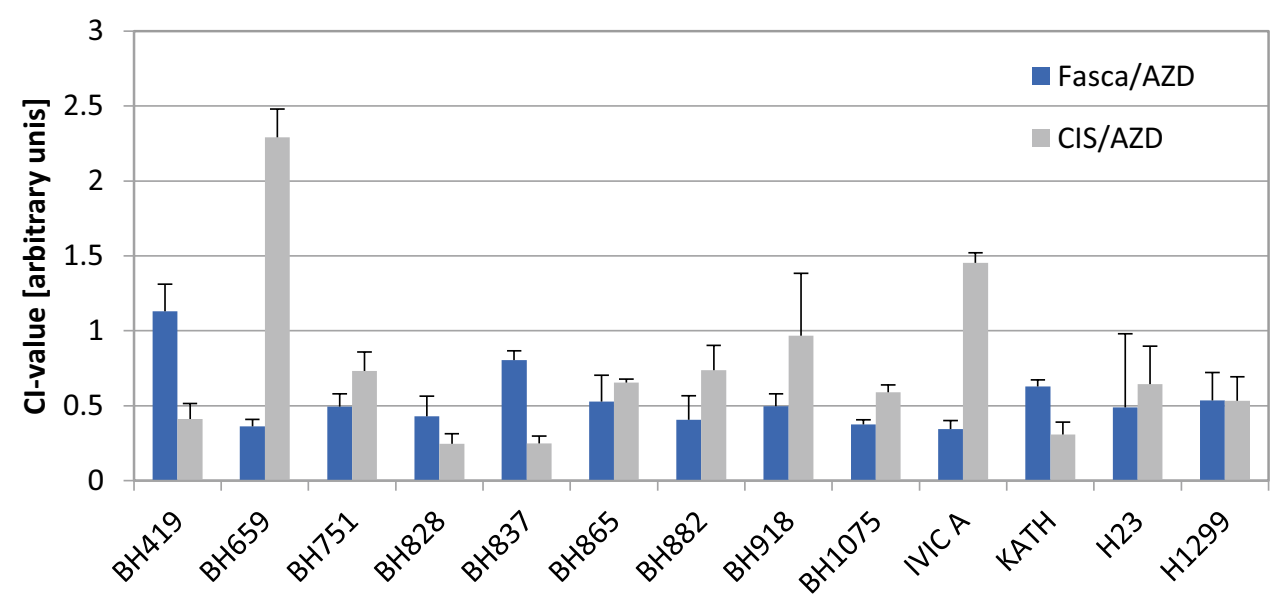


- $6.48 \mu \mathrm{g} / \mathrm{ml}$ ), with $13 / 17$ cell lines exhibiting chemosensitivity below clinical achievable peak plasma concentrations (PPCs) of $3 \mu \mathrm{g} / \mathrm{ml}$ (Fig. 1B). A group with high sensitivity $1.42 \pm 0.79 \mu \mathrm{g} / \mathrm{ml}$ contrasts to a more resistant NSCLC cell population with $6.48 \pm 2.16 \mu \mathrm{g} / \mathrm{ml}$ $(\mathrm{p}=0.001)$. Analysis of the fascaplysin and cisplatin $\mathrm{IC}_{50}$ values showed a lack of correlation (correlation coefficient $r^{2}=0.07$ ) and, thus, completely different chemosensitivities of the primary NSCLC cells to these cytotoxic drugs.

In contrast, $\mathrm{IC}_{50}$ values for afatinib range from $2 \mu \mathrm{M}$ to approximately $8 \mu \mathrm{M}$ indicating relatively low sensitivity for these primary NSCLC cell lines with exception of BH584 and BH659 that have revealed a NSCLC-SCLC transformation (mean $\mathrm{IC}_{50}: 4.81 \pm 2.05 \mu \mathrm{M}$; Fig. 1C). Accordingly, several of these primary NSCLC lines have been obtained after progress under EGFR TKI therapy. The difference in afatinib sensitivity of the permanent cell line H23, H1299, PC-9 and A549 versus primary NSCLC lines is not statistically different. Due to high variability of the IC50 values observed for the permanent lines, differences to primary NSCLC lines were not significant for all drugs.

\section{Cellular toxicity of fascaplysin-afatinib combinations}

The cytotoxic effects of fascaplysin-afatinib combinations were tested in proliferation assays using 10 twofold dilutions of the single drugs and a combination of the two drugs at full concentrations. The effects of the combinations were calculated according to the ChouTalalay method. The combination indices (CIs) are shown in Fig. 2 and all tests revealed synergy of this combination with $\mathrm{CIs}$ ranging from $0.08-0.67$. The mean CI value for the fascaplysin-afatinib combinations and all cell lines was $0.324 \pm 0.19$. For the three ALK-rearranged cell lines, the fascaplysin-alectinib and fascaplysin-crizotinib combinations were synergistic for BH482 and BH827 but not for the alectinib-resistant cell line BH583 (data not shown).

\section{Combinations of fascaplysin and cisplatin with AZD7762}

Combination experiments employing fascaplysin and AZD7762 showed synergistic effects with CI values ranging from $0.35-1.13$ (mean value $0.54 \pm 0.21$ ), except of the BH419 BRCA1-mutated NSCLC cell line. The combinations of cisplatin with AZD7762 showed synergy in 3/13 cell lines (mean value $0.76 \pm 0.53$ ) with $10 / 13$ cell lines being significantly different from fascaplysin-AZD7762 combinations (Fig. 3).

\section{Comparisonof $\mathrm{IC}_{50}$ values of fascaplysin-afatinib combinations versus fascaplysin single drug}

A comparison of the $\mathrm{IC}_{50}$ values of fascaplysin alone with $\mathrm{IC}_{50}$ values obtainted from fascaplysin-afatinib combinations showed significantly increased drug sensitivity of the NSCLC lines in 8/14 cases (Fig. 4).
Fig. 4 depicts the differences of the $\mathrm{IC}_{50}$ values of fascaplysin as single drug and in combination with afatinib. Data represent mean values \pm SD and the statistically significant differences are marked with an asterisk

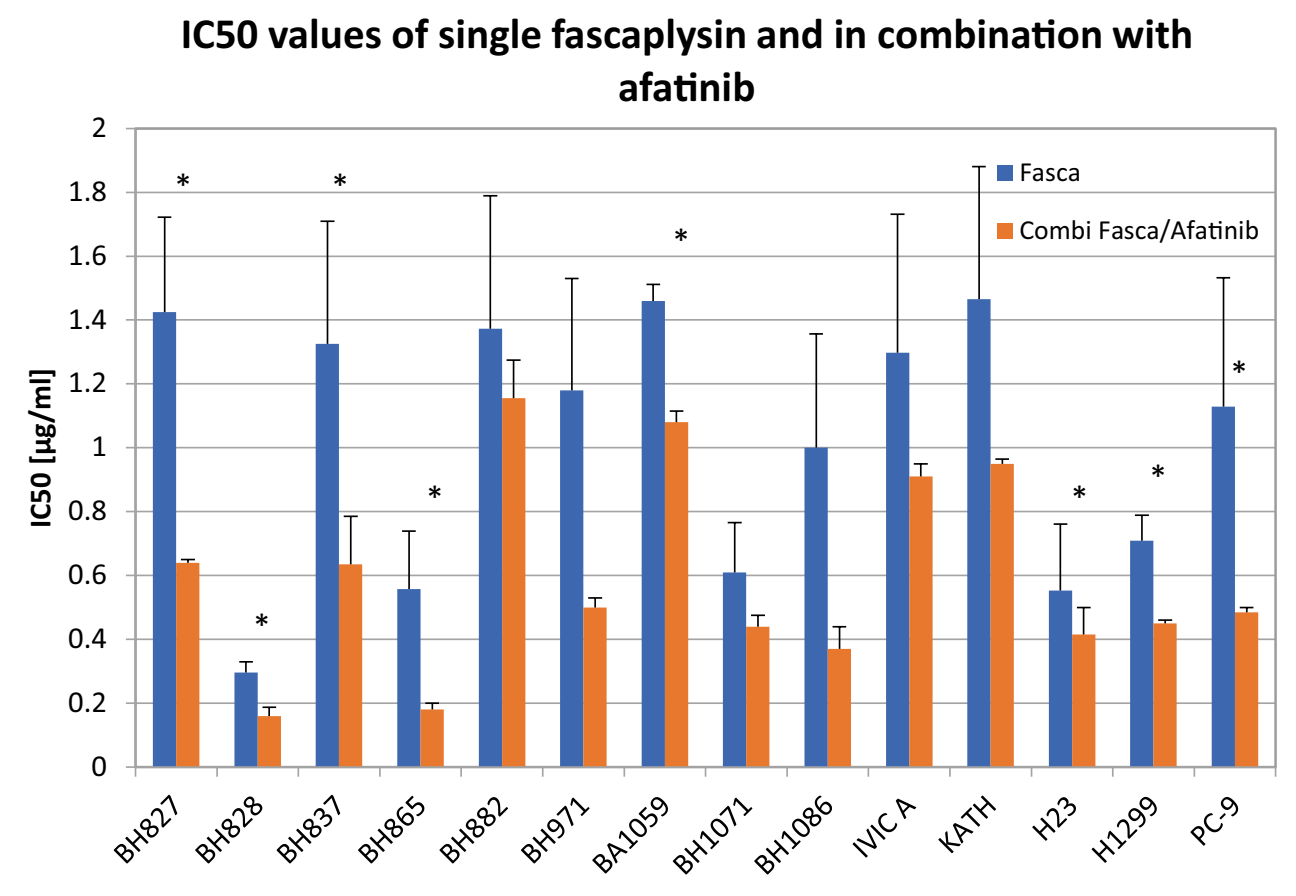


Fig. 5 Out of the whole panel of phosphoproteins, the significantly altered proteins in fascaplysin-treated H1299 cells are presented in Fig. 5. Data presented are mean values $\pm \mathrm{SD}$ of duplicate determinations. All differences betweem H1299 Con and H1299 Fascaplysin are statistically significant

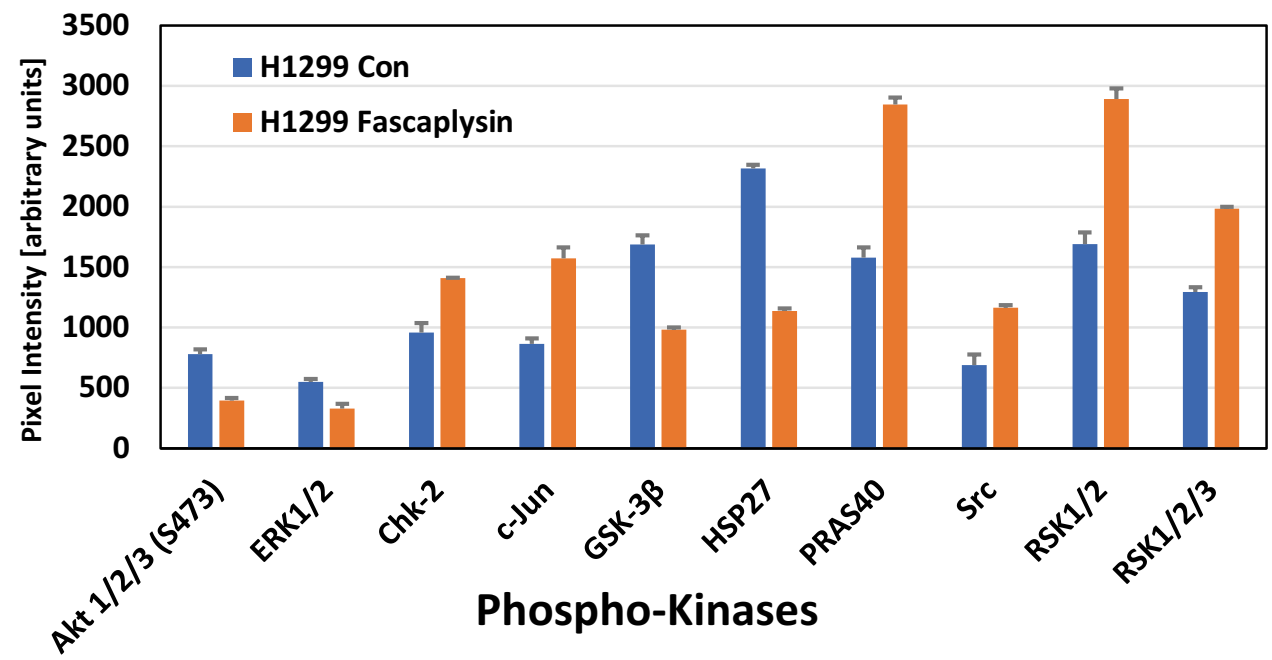

\section{H1299 NSCLC cell line: effects of fascaplysin on protein phosphorylation}

Changes in the phosphorylation of signaling proteins of H1299 cells in response to fascaplysin were analyzed with help of a Western blot profiler array that detects 43 kinase phosphorylation sites and 2 related proteins. Significant changes in the phosphorylation pattern of selected proteins are shown in Fig. 5. Specific sites were hypophosphorylated for Akt1/2/3, ERK1/2, GSK-3 $\beta$ and HSP27, whereas Chk2, src, c-Jun, PRAS40 and RSK1/2/3 become hyperphosphorylated in response to drug exposure.

\section{Discussion}

Therapy of NSCLC has changed dramatically with the advent of TKIs against driver kinases and the activation of antitumor immune responses by monoclonal checkpoint inhibitors (ICIs) [5]. However, the efficacy of such therapeutic modalities is restricted to approximately $30 \%$ of the patients and the majority of advanced NSCLC cases has still to be treated with cytotoxic chemotherapy. However, classical chemotherapy has reached a plateau at a low level in respect to overall survival (OS) [21]. The recent combinations of ICIs with chemotherapy revealed relatively low and unpredictable responses [22, 23]. Thus, novel compounds that hit targets different from that of the platinumbased combinations may improve responses and prolong survival. We have demonstrated previously that fascaplysin has high cytotoxic activity against SCLC, SCLC CTCs and a limited range of NSCLC lines [16]. Here, the chemosensitivity of a panel of primary pleural NSCLC lines against fascaplysin was compared to the cytotoxic effects of cisplatin. The $\mathrm{IC}_{50}$ values for fascaplysin ranged from 0.48 $-1.37 \mu \mathrm{g} / \mathrm{ml}$ for the whole NSCLC cell line panel and from
$1.42-6.48 \mu \mathrm{g} / \mathrm{ml}$ for cisplatin, although most cell lines proved to be cisplatin-sensitive with $\mathrm{IC}_{50}$ values below and around $3 \mu \mathrm{g} / \mathrm{ml}$. Thus, fascaplysin displays considerable cytotoxicity against the primary NSCLC lines that may be further boosted in combination with TKIs directed to EGFR.

The EGFR TKI afatinib is a second generation, irreversible ErbB family blocker, that exhibits inhibitory activity against EGFR, human EGFR 2 (HER2) and 4 (HER4), with $\mathrm{IC}_{50}$ values of $0.5,14$, and $1 \mathrm{nM}$, respectively $[6,24]$. The $\mathrm{IC}_{50}$ afatinib values for the whole primary NSCLC cell line panel of $4.81 \pm 2.05 \mu \mathrm{M}$ is a typical result for cell lines not dependent on mutated EGFR, such as breast cancer cell lines T47D and BT20, whereas $\mathrm{IC}_{50}$ values for afatinib and cell lines addicted to mutated EGFR may be as low as 6-10 nM [25]. At extremes, NSCLC cell lines such as NCI-H460 and NCI-H226 exhibit afatinib $\mathrm{IC}_{50}$ values of approximately $50 \mu \mathrm{M}$. A pharmacokinetics analysis revealed that plasma concentrations of afatinib peaked at $3-4 \mathrm{~h}$ after administration and decreased with a half-life of $37 \mathrm{~h}$ at steady state [26]. Afatinib is administered at $40 \mathrm{mg} \mathrm{PO} /$ day resulting in approximately $0.2 \mu \mathrm{M}$ peak plasma concentration after multiple dosing. Our results show that this TKI in combination with fascaplysin results in approximately twofold sensitization and a considerable decrease of the $\mathrm{IC}_{50}$ values. Although afatinib is the standard drug for the treatment of lung squamous cell carcinoma (SCC) with EGFR overexpression, attempts have been made to use this irreversible blocker for other EGFR expressing tumors. Advanced head and neck squamous cell carcinoma (HNSCC) hold a poor prognosis and tumor progression is associated with overexpression of EGFR [27]. Afatinib increased the cytotoxicity of cisplatin when combined in different schedules of exposure against these HNSCC cell lines. In detail, cisplatin treatment followed by afatinib exposure showed higher activity against two EGFR wildtype HNSCC cell lines 
compared to other approaches. Furthermore, EGFR was found hyperphosphorylated in cisplatin-resistant wildtype EGFR NSCLC cells, $\mathrm{H} 358^{\mathrm{R}}$ and $\mathrm{A} 549^{\mathrm{R}}$, and the cisplatin/ gefitinib combination applied promoted apoptotic cell death [28]. Another study employing five human EGFR wild-type HNSCC cell lines showed significant synergy of afatinib with cisplatin [29]. In detail, in three out of the five cell lines $0.625 \mu \mathrm{M}$ afatinib in combination with cisplatin exerted antiproliferative effects and the remaining two lines showed responses for a combination with $\geq 1.25 \mu \mathrm{M}$ afatinib. Since the EGFR TKI gefitinib showed similar effects to afatinib in sensitizing wildtype EGFR NSCLC cells to cisplatin, the effects of afatinib seem not to be linked by off-target effects due to reactions with non-EGFR protein cysteine residues [30]. In general, the synergistic toxicity may be based on the link of EGFR signaling to the response to DNA damage by chemotherapeutic agents including cisplatin [31].

The induction of the DNA repair system involves sensing of the damage by ATM (ataxia-telangiectasia mutated) and ATR (ATM- and Rad3-Related) kinases and activation of Chk1/2 downstream kinases [32]. The overexpression of Chk1 is associated with poorer outcomes and may contribute to therapy resistance in NSCLC [33]. AZD7762 is a potent inhibitor of Chk1/2 that blocks specifically the ATP binding pocket $\left(\mathrm{IC}_{50} 5 \mathrm{nM}\right)$ [34]. AZD7762 has activity on a range of other kinases SRC family members, colony stimulating factor receptor (CSF1R), RET and others. In combination with DNA-damaging agents such as gemcitabine, topotecan, doxorubicin, and cisplatin, AZD7762 inhibits cancer cell growth in vitro via Chk1 inhibition and abrogation of the G2 and S phase checkpoints [35]. The sensitzing effect of this inhibitor over the DNA-damaging agents alone ranged from 5- to 20-fold. Furthermore, AZD7762 could enhance cisplatin-mediated apoptosis by inhibiting damage repair in vitro and enhanced xenograft apoptosis induced by cisplatin in vivo [36]. Surprisingly, in our experiments the synergistic effect of AZD7762 on tumor cell death proved to be higher in fascaplysin-AZD7762 combinations versus cisplatin-AZD7762 combinations. Studies has shown that the intercalation of fascaplysin is regarded as the major binding mode for DNA [37]. Fascaplysin displaces ethidium bromide from DNA that is known to bind to the minor groove of doublestrand DNA and, therefore, intercalation is hold to be responsible for the unique cytotoxicity of native fascaplasin versus nonplanar derivatives and induction of the DNA repair system [38].

Investigation of fascaplysin-induced changes in protein phosphorylation in H1299 NSCLC cells was assessed using Western blot arrays, as previously demonstrated for the A549 cell line [16]. The PI3K/AKT/mTOR pathway, which plays essential roles in cell proliferation and survival is frequently deregulated in cancer, in particular due to loss of PTEN, as in the case of H1299 [39]. The fascaplysin-induced decreases in Akt (Ser473) phosphorylation are correlated with lower cell survival due to induction of apoptosis [40]. Decreased phosphorylation of the mitogen-activated protein kinase (MAPK) pathway terminal master kinases ERK1/2 results in diminished proliferation and was found here for the exposure to fascaplysin, [41]. Chk2 and Chk1 phosphorylation triggers DNA repair and hyperphosphorylation of c-Jun and Src which is linked to the cellular stress response [42]. Hypophosphorylation of multifunctional glycogen synthase kinase $3 \beta$ (GSK3 $\beta$ ) alters a key node of survival pathways mediated by Ser/ Thr protein kinases related to Akt, protein kinase C (PKC), ERK1/2 and Wnt [43]. Furthermore, hypophosphorylation of the chaperone HSP27 is known to enhance the cytotoxicity of chemotherapeutics [44]. The p90 ribosomal S6 kinases (RSK1-4) comprise a family of serine/threonine kinases that lie at the terminus of the ERK pathway. RSKs promotes silencing of G2 DNA damage checkpoint in a Chk1-dependent manner, and activation of RSKs promotes resistance to DNA-damaging agents [45]. The cell stress response observed in $\mathrm{H} 1299$ seems to result in activation of the RSK kinases. The proline-rich Akt substrate of $40 \mathrm{kDa}$ (PRAS40) is a substrate of Akt and is phosphorylated by growth factors or other stimuli. PRAS40 is an important substrate of the Akt3 kinase, which regulates the apoptotic sensitivity of cancer cells and becomes activated in H1299 to counteract the cytotoxic effects of fascaplysin [46]. The fascaplysin-induced alterations in protein phosphorylation indicate efficient execution of cytotoxic effects and a failing intracellular stress response.

In summary, fascaplysin promotes cell death of NSCLC cell line in a manner different from the standard platinum drugs. This marine drug induces a DNA repair response, syngergizes with the Chk1/2 inhibitor AZD7762 and with the EGFR TKI afatinib.

Acknowledgements We wish to thank Dr. T. Hohenheim for continuous endorsement.

Author Contributions All authors contributed to the study conception and design. Material preparation, experimentation, data collection and analysis were performed by M. Hochmair, A. Plangger, B. Rath and G. Hamilton. M. Funovic, C. Neumayer and R. Zeillinger were involved in the establishment of the cell lines, funding and review of the results. All authors participated in writing the first draft of the manuscript and subsequent corrections. All authors have read and approved the final version of the manuscript.

Funding Open access funding provided by Medical University of Vienna. This research was funded in part by the grant number 19090 to Christoph Neumayer by the "Medical Scientific Fund of the Mayor of the City of Vienna "grant number 19090.

Data availability All data and materials are available under reasonable request. 


\section{Declarations}

Ethics approval The collection of patient's samples and experimentation was done according to the Ethics Approval 366/2003 by the Ethics Committee of the Medical University of Vienna, Vienna, Austria.

Informed consent In accordance with the Ethics approval 366/2003, informed consent was obtained from all participants included in the collection of pleural effusions.

Consent for publication All authors consented to publish this study in the journal of Investigational New Drugs.

Competing interests All authors declare no conflict of interest. The authors declare no conflict of interest related to the present work.

Open Access This article is licensed under a Creative Commons Attribution 4.0 International License, which permits use, sharing, adaptation, distribution and reproduction in any medium or format, as long as you give appropriate credit to the original author(s) and the source, provide a link to the Creative Commons licence, and indicate if changes were made. The images or other third party material in this article are included in the article's Creative Commons licence, unless indicated otherwise in a credit line to the material. If material is not included in the article's Creative Commons licence and your intended use is not permitted by statutory regulation or exceeds the permitted use, you will need to obtain permission directly from the copyright holder. To view a copy of this licence, visit http://creativecommons.org/licenses/by/4.0/.

\section{References}

1. Jones GS, Baldwin DR (2018) Recent advances in the management of lung cancer. Clin Med (Lond) 18(Supp12):s41-s46. https://doi.org/10.7861/clinmedicine.18-2-s41

2. Simeone JC, Nordstrom BL, Patel K, Klein AB (2019) Treatment patterns and overall survival in metastatic non-small-cell lung cancer in a real-world. US setting Future Oncol 15(30):34913502. https://doi.org/10.2217/fon-2019-0348

3. Christofi T, Baritaki S, Falzone L, Libra M, Zaravinos A (2019) Current Perspectives in Cancer Immunotherapy Cancers (Basel) 11(10):1472. https://doi.org/10.3390/cancers11101472

4. Doroshow DB, Sanmamed MF, Hastings K et al (2019) Immunotherapy in Non-Small Cell Lung Cancer: Facts and Hopes. Clin Cancer Res 25(15):4592-4602. https://doi.org/10.1158/10780432.CCR-18-1538

5. Yuan M, Huang LL, Chen JH, Wu J, Xu Q (2019) The emerging treatment landscape of targeted therapy in non-small-cell lung cancer. Signal Transduct Target Ther 4:61. https://doi.org/10. 1038/s41392-019-0099-9

6. Solca F, Dahl G, Zoephel A, Bader G, Sanderson M, Klein C et al (2012) Target binding properties and cellular activity of afatinib (BIBW 2992), an irreversible ErbB family blocker. J Pharmacol Exp Ther 343:342-350. https://doi.org/10.1124/jpet.112.197756

7. Modjtahedi H, Cho BC, Michel MC, Solca F (2014) A comprehensive review of the preclinical efficacy profile of the ErbB family blocker afatinib in cancer. Naunyn Schmiedebergs Arch Pharmacol 387:505-521. https://doi.org/10.1007/s00210-014-0967-3

8. Mathew M, Enzler T, Shu CA, Rizvi NA (2018) Combining chemotherapy with PD-1 blockade in NSCLC. Pharmacol Ther 186:130-137. https://doi.org/10.1016/j.pharmtherap.2018.01.003
9. Lyakhova I, Piatkova M, Gulaia V et al (2020) Alkaloids of fascaplysin are promising chemotherapeutic agents for the treatment of glioblastoma: Review. Int Rev Neurobiol 151:299-324. https:// doi.org/10.1016/bs.irn.2020.03.010

10. Bharate SB, Manda S, Mupparapu N, Battini N, Vishwakarma RA (2012) Chemistry and biology of fascaplysin, a potent marinederived CDK-4 inhibitor. Mini Rev Med Chem 12(7):650-664. https://doi.org/10.2174/138955712800626719

11. Lyakhova I, Piatkova M, Khotimchenko Y et al (2020) 3Bromofascaplysin is a prospective chemical compound for developing new chemotherapy agents in glioblastoma treatment. Int Rev Neurobiol 151:325-343. https://doi.org/10.1016/bs.irn.2020.03.011

12. Oh TI, Lee JH, Kim S et al (2017) Fascaplysin Sensitizes AntiCancer Effects of Drugs Targeting AKT and AMPK. Molecules 23(1):42. https://doi.org/10.3390/molecules23010042

13. Chen S, Guan X, Wang LL et al (2017) Fascaplysin inhibit ovarian cancer cell proliferation and metastasis through inhibiting CDK4. Gene 635:3-8. https://doi.org/10.1016/j.gene.2017.09.009

14. Soni R, Muller L, Furet $P$ et al (2000) Inhibition of cyclin-dependent kinase 4 (Cdk4) by fascaplysin, a marine natural product. Biochem Biophys Res Commun 275(3):877-884

15. Hamilton G (2014) Cytotoxic effects of fascaplysin against small cell lung cancer cell lines. Mar Drugs 12(3):1377-1389. https://doi.org/10.3390/md12031377

16. Rath B, Hochmair M, Plangger A, Hamilton G (2018) Anticancer Activity of Fascaplysin against Lung Cancer Cell and Small Cell Lung Cancer Circulating Tumor Cell Lines. Mar Drugs 16(10):383. https://doi.org/10.3390/md16100383

17. Andrew G, Villanueva AG (2012) Management of malignant pleural effusions. Principles and Practice of Interventional Pulmonology. 64:665-674 In: A Ernst, FJF Herth (eds) Principles and Practice of Interventional Pulmonology 665. https://doi.org/10.1007/978-1-4614-4292-9_64.

18. Roscilli G, De Vitis C, Ferrara FF et al (2016) Human lung adenocarcinoma cell cultures derived from malignant pleural effusions as model system to predict patients chemosensitivity. J Transl Med 14:61. https://doi.org/10.1186/s12967-016-0816-X

19. Ruan X, Sun Y, Wang W et al (2020) Multiplexed molecular profiling of lung cancer with malignant pleural effusion using next generation sequencing in Chinese patients. Oncol Lett 19(5):3495-3505. https://doi.org/10.3892/ol.2020.11446

20. Ruiz C, Kustermann S, Pietilae E et al (2016) Culture and Drug Profiling of Patient Derived Malignant Pleural Effusions for Personalized Cancer Medicine. PLoS ONE 11(8):e0160807. https://doi.org/10.1371/journal.pone.0160807

21. Rossi A, Di Maio M (2016) Platinum-based chemotherapy in advanced non-small-cell lung cancer: optimal number of treatment cycles. Expert Rev Anticancer Ther 16(6):653-660. https://doi.org/10.1586/14737140.2016.1170596

22. Hochmair M (2020) Resistance to chemoimmunotherapy in nonsmall-cell lung cancer. Cancer Drug Resist 3:445-453. https:// doi.org/10.20517/cdr.2020.09

23. Hamilton G (2020) Avelumab: search for combinations of immune checkpoint inhibition with chemotherapy. Expert Opin Biol Ther 3:1-12. https://doi.org/10.1080/14712598.2021.1825679

24. Abdallah SM, Hirsh V (2018) Irreversible tyrosine kinase inhibition of epidermal growth factor receptor with afatinib in EGFR activating mutation-positive advanced non-small-cell lung cancer. Curr Oncol 25(Suppl 1):S9-S17. https://doi.org/ $10.3747 / \mathrm{co} .25 .3732$

25. https://www.selleckchem.com, last accessed 10.03.2020

26. Wind S, Schnell D, Ebner T, Freiwald M, Stopfer P (2017) Clinical Pharmacokinetics and Pharmacodynamics of Afatinib. Clin Pharmacokinet 56(3):235-250. https://doi.org/10.1007/ s40262-016-0440-1 
27. Longton E, Schmit K, Fransolet M, Clement F, Michiels C (2018) Appropriate Sequence for Afatinib and Cisplatin Combination Improves Anticancer Activity in Head and Neck Squamous Cell Carcinoma. Front Oncol 8:432. https://doi.org/10.3389/fonc. 2018.00432

28. Li A, Cao W, Liu X et al (2020) Gefitinib sensitization of cisplatin-resistant wild-type EGFR non-small cell lung cancer cells. J Cancer Res Clin Oncol 146(7):1737-1749. https://doi.org/10. 1007/s00432-020-03228-4

29. Brands RC, Muller-Richter UD, De Donno F, Seher A, Mutzbauer G, Linz C et al (2016) Co-treatment of wild-type EGFR head and neck cancer cell lines with afatinib and cisplatin. Mol Med Rep 13:2338-2344. https://doi.org/10.3892/mmr.2016.4786

30. Raimbourg J, Joalland MP, Cabart M et al (2017) Sensitization of EGFR Wild-Type Non-Small Cell Lung Cancer Cells to EGFRTyrosine Kinase Inhibitor Erlotinib. Mol Cancer Ther 16(8):16341644. https://doi.org/10.1158/1535-7163.MCT-17-0075

31. Benhar M, Engelberg D, Levitzki A (2002) Cisplatin-induced activation of the EGF receptor. Oncogene 21:8723-8731. https:// doi.org/10.1038/sj.onc. 1205980

32. Smith HL, Southgate H, Tweddle DA, Curtin NJ (2020) DNA damage checkpoint kinases in cancer. Expert Rev Mol Med 22:e2. https://doi.org/10.1017/erm.2020.3 (PMID: 32508294)

33. Grabauskiene S, Bergeron EJ, Chen G, Thomas DG, Giordano TJ, Beer DG, Morgan MA, Reddy RM (2014) Checkpoint kinase 1 protein expression indicates sensitization to therapy by checkpoint kinase 1 inhibition in non-small cell lung cancer. J Surg Res 187(1):6-13. https://doi.org/10.1016/j.jss.2013.12.016

34. Zabludoff SD, Deng C, Grondine MR, Sheehy AM, Ashwell S, Caleb BL, Green S, Haye HR, Horn CL, Janetka JW, Liu D, Mouchet E, Ready S, Rosenthal JL, Queva C, Schwartz GK, Taylor KJ, Tse AN et al (2008) AZD7762, a novel checkpoint kinase inhibitor, drives checkpoint abrogation and potentiates DNA-targeted therapies. Mol Cancer Ther 7(9):2955-2966. https://doi.org/10.1158/1535-7163. MCT-08-0492

35. Walker GE, White AM (2008) AZD7762, a novel checkpoint kinase inhibitor, drives checkpoint abrogation and potentiates DNA-targeted therapies. Mol Cancer Ther 7(9):2955-2966. https://doi.org/10.1158/1535-7163.MCT-08-0492

36. Zhu J, Zou H, Yu W, Huang Y, Liu B, Li T, Liang C, Tao H (2019) Checkpoint kinase inhibitor AZD7762 enhance cisplatin-induced apoptosis in osteosarcoma cells. Cancer Cell Int 19:195. https:// doi.org/10.1186/s12935-019-0896-9
37. Hörmann A, Chaudhuri B, Fretz H (2001) DNA binding properties of the marine sponge pigment fascaplysin. Bioorg Med Chem 9(4):917-921. https://doi.org/10.1016/s0968-0896(00)00313-8

38. Mahale S, Bharate SB, Manda S, Joshi P, Jenkins PR, Vishwakarma RA, Chaudhuri B (2015) Antitumour potential of BPT: a dual inhibitor of cdk4 and tubulin polymerization. Cell Death Dis 6(5):e1743. https://doi.org/10.1038/cddis.2015.96

39. Soria JC, Lee HY, Lee JI, Wang L, Issa JP, Kemp BL, Liu DD, Kurie JM, Mao L, Khuri FR (2002) Lack of PTEN expression in non-small cell lung cancer could be related to promoter methylation. Clin Cancer Res 8(5):1178-1184

40. Guo Y, Du J, Kwiatkowski DJ (2013) Molecular dissection of AKT activation in lung cancer cell lines. Mol Cancer Res 11(3):282-293. https://doi.org/10.1158/1541-7786

41. Mebratu Y, Tesfaigzi Y (2009) How ERK1/2 activation controls cell proliferation and cell death: Is subcellular localization the answer? Cell Cycle 8(8):1168-1175. https://doi.org/10.4161/cc.8. 8.8147

42. Johnson GL, Nakamura K (2007) The c-jun kinase/stress-activated pathway: regulation, function and role in human disease. Biochim Biophys Acta 1773(8):1341-1348. https://doi.org/10.1016/j. bbamcr.2006.12.009

43. Venè R, Cardinali B, Arena G, Ferrari N, Benelli R, Minghelli S, Poggi A, Noonan DM, Albini A, Tosetti F (2014) Glycogen synthase kinase 3 regulates cell death and survival signaling in tumor cells under redox stress. Neoplasia 16(9):710-722. https:// doi.org/10.1016/j.neo.2014.07.012

44. Shevtsov M, Multhoff G, Mikhaylova E, Shibata A, Guzhova I, Margulis B (2019) Combination of Anti-Cancer Drugs with Molecular Chaperone Inhibitors. Int J Mol Sci 20(21):5284. https://doi.org/10.3390/ijms20215284

45. Ray-David H, Romeo Y, Lavoie G, Déléris P, Tcherkezian J, Galan JA, Roux PP (2013) RSK promotes G2 DNA damage checkpoint silencing and participates in melanoma chemoresistance. Oncogene 32(38):4480-4489. https://doi.org/10.1038/onc.2012.472

46. Madhunapantula SV, Sharma A, Robertson GP (2007) PRAS40 deregulates apoptosis in malignant melanoma. Cancer Res 67(8):3626-3636. https://doi.org/10.1158/0008-5472. CAN-06-4234

Publisher's Note Springer Nature remains neutral with regard to jurisdictional claims in published maps and institutional affiliations. 